\title{
Family structure and functioning: Influences on adolescents psychological needs, goals and aspirations in a South African setting
}

Eugene Lee Davids, Jill Ryan, Zeenat Yassin, Suzette Hendrickse and Nicolette Vanessa Roman

\begin{abstract}
This study aimed to determine the effects of family structure and functioning on basic psychological need fulfilment, life goals and aspirations of adolescents in a South African setting. Participants were 457 adolescent learners $\left(M_{\text {age }}=16.31, \mathrm{SD}=1.45\right.$, females $=54 \%$, coloured $=56 \%$ ) selected from four public schools in the Western Cape, South Africa. The adolescents completed the Family Assessment Device, Aspirations Index and Psychological Needs Scales. Results following multiple regression analysis suggested that a two-parent family structure predicted higher satisfaction of basic psychological needs and higher pursuit of extrinsic goals among adolescents than did a one -parent family structure. Family functioning determined pursuit of intrinsic goals by adolescents from one-parent families.
\end{abstract}

\section{Introduction}

Adolescence is a developmental stage marked by self- discovery, decision-making and the formation of important life aspirations (La Guardia \& Ryan, 2002; Heubner \& Howell, 2003). The phase of adolescence is important from a developmental perspective, as it is during this phase that a number of choices and alternatives present themselves in daily interaction where decisions need to be made regarding life goals and aspirations (Zarrett \& Eccles, 2006).

It also is a stage in which unique psychological identity needs arise as a result of adolescents' increased self-awareness (Deci \& Ryan, 2008). However, social environments may either accentuate or attenuate related personal growth processes of adolescents (Ryan \& Deci, 2004). The family is one such key social environment. Decision-making in aspiring towards certain life goals and aspirations occurs within the familial home environment (Davids, Roman \& Leach, 2016). For instance, whether the adolescent's family structure is a one-parent or two-parent family may influence their life aspirations and salient psychological needs in different ways (Deci \& Ryan, 200o; Ryan \& Deci, 2004; Davids \& Roman, 2013). Related studies on the influences of family structure have been conducted mostly in developed Western settings; the generalisability of these to developing country settings is unclear (Jennings \& Barber, 2013; Meinck, Cluver, Boyes \& 
Mhlongo, 2015; Stuart, Ward \& Robinson, 2016). This study investigated family structure and functioning influences on the psychological needs, as well as the life goals and aspirations, of adolescents in South Africa, a developing country with a social fabric broadly similar to many countries in southern Africa.

\section{Family structure in South Africa}

Family structure refers to different family forms identified as blended families, single-parent families, married or cohabiting parent families, extended families and child-headed families. In the current study, the focus is on one-parent and two-parent families (Voydanoff, 2001). Research carried out in South Africa in 2011 (Holborn \& Eddy, 2011) indicated that 35 per cent of children lived with both biological parents, while 42.8 per cent were in one-parent families. Of these one-parent families, 40 per cent of children resided with their mothers and 2.8 per cent with their fathers. The remaining 22.6 per cent of children resided with neither of their biological parents (Holborn \& Eddy, 2011). Previous studies reported that children from one-parent families were more likely to experience negative outcomes such as delinquent behaviour compared to those from two-parent families (McLanahan \& Sandefur, 1994; Amato, 2005; Nqweni, Pinderhughes \& Hurley, 2010). Diminished well-being of children in single-parent families may result from lower levels of parental monitoring (Waldfogel, Craigie \& Brooks-Gunn, 2010; Basson, 2013). By contrast, children from two-parent families may be socially advantaged with shared parental monitoring (Thomas \& Sawhill, 2005; Fomby \& Cherlin, 2007; Olaniyi \& Narain, 2008; Waldfogel et al., 2010). However, two-parent families may not fare any better in cases where children are exposed to chronic parental conflict within the home (Slep \& O'Leary, 2005). These hostile environments have been shown to be much worse than circumstances experienced by children of single parents (Amato, 2005).

In South Africa, a study by Davids and Roman (2013) showed significant differences in life goals and aspirations between adolescents from one-parent and two-parent families. They found that one-parent family adolescents aspired more towards goals that were intrinsic in nature. However, family structure may explain only a part of the overall influences on the goals and aspirations of South African adolescents. Family functioning may also contribute to the ways in which adolescents conceive their goals and aspirations. For example, Roman (2011) found no differences between one- and two-parent families in terms of parent-child relationships. Additional research may clarify the role of family structure in affecting the psychological needs, as well as the life goals and aspirations, of adolescents.

\section{Family functioning}

Family functioning refers to the organisational properties and interpersonal interactions among familial members, including problem-solving, warmth, closeness, adaptability, roles, behaviour control and communication (Berge, Wall, Larson, Loth, \& NeumarkSztainer, 2013). Epstein, Baldwin and Bishop (1983) identified six features of a healthy, wellfunctioning family, namely the ability to solve problems, effective communication, appropriate role allocation, affective responsiveness, empathetic affective involvement and the 
application of flexible behaviour control. A family characterised by these conditions allows for the satisfaction of the basic psychological needs of adolescents.

\section{Psychological needs}

Generally, psychological needs include being self-determining in goal-seeking (intrinsic goals) and being externally goal-driven by others (extrinsic goals), and maintaining satisfying interpersonal relationships. The pursuit of intrinsic goals is associated with the optimal development and well-being of adolescents, as these goals are geared towards affiliation, self-actualisation, personal growth and community contributions (Kasser \& Ryan, 1993; Kasser \& Ryan, 1996; Deci \& Ryan, 2008; Disabato, Goodman, Kashdan, Short \& Jarden, 2016). By contrast, extrinsic goals lead to the pursuit of wealth, fame and image and are associated with long-term implications for the well-being of adolescents and social interrelationships (Kasser \& Ryan, 1993, 1996; Davids \& Roman, 2013). However, the extent to which adolescent intrinsic or extrinsic goals are influenced by family structure is unknown.

Various South African studies have explored families in terms of well-being (Koen, Van Eeden \& Rothmann, 2013), family structure and life goals (Davids \& Roman, 2013), family structure and parenting (Roman, 2011; Davids, Roman \& Leach, 2015) and healthy family functioning (Zwane, Venter, Temane \& Chigeza, 2012), but not family structure and functioning effects on psychological need fulfilment, goals and aspirations among adolescents. The following question guided the study: How does family structure and functioning influence psychological needs, goals and aspirations among South African adolescents?

\section{Method}

\section{Participants}

A total of 457 adolescents were randomly selected from four schools in the Western Cape, South Africa. They were all in the Ninth Grade. The participants had a mean age of 16.31 years $(\mathrm{SD}=1.45)$, and $243(53.8 \%)$ were female. The prevalent racial identification of participants was coloured $(n=248 ; 56.4 \%)$, followed by black African ( $n$ $=186 ; 42.3 \%)$ and white $(n=6 ; 1.4 \%)$. The majority of participants spoke Afrikaans $(n=$ $253 ; 56.5 \%)$, followed by isiXhosa $(n=166 ; 37.1 \%)$ and English $(n=3 ; 0.7 \%)$. Twenty-six (5.8\%) of the participants indicated that they spoke languages that were categorised as 'other'.

\section{Procedure}

The University of the Western Cape granted ethics approval for the study, after which permission was granted by the Western Cape Education Department to access schools for study. School principals and parents of the children consented to the study. The learners assented to the study. Data was collected during normal school hours. The self-administered questionnaires took approximately 35 minutes to complete. 


\section{Measures}

The adolescents self-reported their demographic data (age, one- or two-parent family, home language, gender). In addition, they completed a family functioning measure (Family Assessment Device: Epstein, Baldwin \& Bishop, 1983), a measure of life aspirations (Aspirations Index: Kasser \& Ryan, 1996) and of basic psychological needs (Psychological Needs Scale: Sheldon \& Hilpert, 2012).

The Family Assessment Device is a 60-item measure of general family functioning, as either being stressed (which would be detrimental to the familial functioning) or non-stressed (which would augment family functioning). A score of between 1.68 and 2.00 indicated stressed family functioning, while a score of 1.49 or less indicated non-stressed family functioning. The Cronbach alpha for scores for the general family functioning scale was 0.81 for the present sample.

The Aspirations Index is a 35-item measure of life goals and aspirations of individuals across seven goal domains (wealth, fame, image, personal growth, relationship, community and health) which were used to create the variables for intrinsic and extrinsic goals and aspirations. Participants respond on a four-point Likert scale (ranging from $1=$ 'somewhat important', to 4 = 'very important'). In the present sample, scores from the intrinsic goals subscale achieved a Cronbach alpha score of 0.89 , while those from the extrinsic goals subscale achieved an alpha score of 0.72 .

The Psychological Needs Scale assesses the satisfaction and frustration of the three basic psychological needs, namely competence, autonomy and relatedness. The scale is made up of 18 items. It is scored on a four-point Likert scale (ranging from $1=$ 'not at all true', to 4 $=$ 'very true'). The Cronbach alpha score for this scale in the present sample was o.63.

\section{Data analysis}

The data was analysed using the Statistical Package for the Social Sciences (SPSS) version 23. Hierarchical regression analysis was used to predict psychological needs and goal types (intrinsic versus extrinsic) according to family structure, taking into account family functioning.

\section{Results}

Tables 1 and 2 present descriptive statistics and a correlation matrix of the study variables. As can be observed from Table 1, the participants aspired more towards intrinsic goals in both one-parent $(M=2.91, \mathrm{SD}=1.05)$ and two-parent family structures $(M=2.97, \mathrm{SD}=1.08)$. The experience of basic psychological need satisfaction was moderately high in both one-parent $(M=2.91, \mathrm{SD}=0.48)$ and two-parent families $(M=$ 3.00, $\mathrm{SD}=0.47)$. Perceived family functioning was considered within normal range for both one- and two-parent families $(M=0.31, \mathrm{SD}=0.38$, and $M=0.30, \mathrm{SD}=0.36)$ respectively. 
Table 1: Means and standard deviations for the study variables

\begin{tabular}{lllll}
\hline & & Total sample & One parent & Two parents \\
\hline Variable & & Mean (SD) & Mean (SD) & Mean (SD) \\
\hline Goals & Intrinsic goals & $2.94(1.07)$ & $2.91(1.05)$ & $2.97(1.08)$ \\
& Extrinsic goals & $2.75(.57)$ & $2.65(.62)$ & $2.81(.52)$ \\
\hline Basic psychological needs & Need satisfaction & $2.96(.48)$ & $2.91(.48)$ & $3.00(.47)$ \\
& Need frustration & $2.45(.49)$ & $2.44(.50)$ & $2.48(.50)$ \\
\hline Family functioning ${ }^{1}$ & General functioning & $0.30(.37)$ & $0.31(.38)$ & $0.30(.36)$ \\
\hline${ }^{1}$ Reversed family functioning scores: $\geq 1.49$ = no stress, $1.50-1.68=$ stressed, $\leq 2.00=$ problematic family functioning & &
\end{tabular}

Table 2: Zero-order correlations among the study variables

\begin{tabular}{|c|c|c|c|c|c|c|}
\hline \multirow{2}{*}{\multicolumn{7}{|c|}{ One parent }} \\
\hline & & 1 & 2 & 3 & 4 & 5 \\
\hline 1 & Extrinsic & 1 & & & & \\
\hline 2 & Intrinsic & $0.50^{* *}$ & 1 & & & \\
\hline 3 & Need sat & 0.10 & $0.17^{*}$ & 1 & & \\
\hline 4 & Need frust & -0.01 & -0.02 & $0.30^{* *}$ & 1 & \\
\hline 5 & Gen funct & 0.03 & $0.23 * *$ & -0.00 & -0.08 & 1 \\
\hline \multicolumn{7}{|c|}{ Two parents } \\
\hline & & 1 & 2 & 3 & 4 & 5 \\
\hline 1 & Extrinsic & 1 & & & & \\
\hline 2 & Intrinsic & $0.41^{* *}$ & 1 & & & \\
\hline 3 & Need sat & $0.24^{* *}$ & $0.24^{* *}$ & 1 & & \\
\hline 4 & Need frust & 0.13 & 0.10 & $0.14 *$ & 1 & \\
\hline 5 & Gen funct & -0.07 & $0.13^{*}$ & 0.01 & 0.03 & 1 \\
\hline
\end{tabular}

Pursuit of extrinsic goals was significantly correlated with basic psychological need satisfaction $(r=0.24, p \leq 0.01)$ in two-parent family structures only, while intrinsic goals were significantly correlated with basic psychological need satisfaction and general family functioning in both one-parent $(r=0.17, p \leq 0.05 ; r=0.23, p \leq 0.01)$ and two-parent $(r=$ $0.24, p \leq 0.01 ; r=0.13, p \leq 0.05$ ) structures (see Table 2). No significant correlations were found for basic psychological need frustration.

Predicting intrinsic and extrinsic goals and aspirations Tables 3 and 4 present the results of the hierarchical regression analyses in predicting intrinsic and extrinsic life goals. In Step 1, intrinsic and extrinsic life goals were regressed on the satisfaction and frustration of basic psychological needs. In Step 2, intrinsic and extrinsic goals were regressed to general family functioning which was added in this step of the regression analyses.

\section{Intrinsic goals}

In Step 1, basic psychological need satisfaction significantly and positively predicted intrinsic goals for both the one-parent $(\beta=0.20, p<0.001)$ and two-parent $(\beta=0.24, p<$ 0.001) family structures. In Step 2, which included general family functioning, basic psychological need satisfaction also significantly predicted intrinsic goals for both oneand two-parent family structures. Similarly, general family functioning $(\beta=0.21, p<$ o.001) significantly and positively predicted intrinsic goals for one-parent family 
structures only. The final model explained six per cent of the variance for intrinsic goals (see Table 3).

\section{Extrinsic goals}

In Step 1, basic psychological need satisfaction $(\beta=0.24, p<0.001)$ was a positive, significant predictor for extrinsic goals for two-parent family structures only. In Step 2, only basic psychological need satisfaction remained a positive significant predictor for extrinsic goals for two-parent family structures. The final model explained six per cent of the variance for extrinsic goals (see Table 4).

\section{Discussion}

If the basic psychological needs of adolescents are satisfied, they might aspire to more intrinsic life goals regardless of whether they have one or two parents. Furthermore, being in a one-parent family with moderate to high general family functioning will predict aspiring to intrinsic life goals and aspirations, while in two-parent families, aspiring to extrinsic life goals is predicted by need satisfaction. This finding of aspiring towards goals and aspirations that were more intrinsic in both one- and two-parent families is contrary to findings of previous studies conducted in South Africa where the most prevalent goals and aspirations were extrinsic (Davids \& Roman, 2013; Roman et al., 2015). The present findings may be explained by the fact that South African adolescents may aspire to life goals which are for personal growth rather than life goals such as wealth and fame (McLachlan \& Haggar, 2011; Davids \& Roman, 2013).

Table 3: Regression of intrinsic goals on family structure with general family functioning

\begin{tabular}{|c|c|c|c|c|c|c|c|c|c|c|c|c|}
\hline \multirow[b]{2}{*}{ Intrinsic goals } & \multicolumn{4}{|c|}{ Total sample } & \multicolumn{4}{|c|}{ One parent } & \multicolumn{4}{|c|}{ Two parents } \\
\hline & $b$ & $\mathrm{SE} b$ & $B$ & $t$ & $b$ & $\mathrm{SE} b$ & $B$ & $t$ & $b$ & $\mathrm{SE} b$ & $B$ & $t$ \\
\hline \multicolumn{13}{|l|}{ Step 1} \\
\hline Constant & 1.61 & & & & 2.12 & & & & 1.17 & & & \\
\hline Need satisfaction & 0.46 & 0.11 & $0.22 *$ & 4.40 & 0.41 & 0.16 & $0.20 *$ & 2.48 & 0.51 & 0.14 & $0.24^{*}$ & 3.59 \\
\hline Need frustration & 0.01 & 0.10 & 0.01 & 0.09 & -0.15 & 0.16 & -0.07 & -0.92 & 0.14 & 0.13 & 0.07 & 1.03 \\
\hline \multicolumn{13}{|l|}{ Step 2} \\
\hline Constant & 1.47 & & & & 1.88 & & & & 1.10 & & & \\
\hline Need satisfaction & 0.46 & 0.10 & $0.22 *$ & 4.43 & 0.40 & 0.16 & $0.19 *$ & 2.47 & 0.50 & 0.14 & $0.24 *$ & 3.60 \\
\hline Need frustration & 0.02 & 0.10 & 0.01 & 0.15 & -0.11 & 0.16 & -0.05 & -0.70 & 0.13 & 0.13 & 0.06 & 0.98 \\
\hline General functioning & 0.41 & 0.13 & $0.15^{*}$ & 3.19 & 0.56 & 0.19 & $0.21^{*}$ & 2.90 & 0.28 & 0.18 & 0.10 & 1.52 \\
\hline Step 1: & \multicolumn{4}{|c|}{ Intrinsic goals: $\Delta R^{2}=0.04$} & \multicolumn{4}{|c|}{ Intrinsic goals: $\Delta R^{2}=0.02$} & \multicolumn{4}{|c|}{ Intrinsic goals: $\Delta R^{2}=0.06$} \\
\hline Step 2: & \multicolumn{4}{|c|}{ Intrinsic goals: $\Delta R^{2}=0.06$} & \multicolumn{4}{|c|}{ Intrinsic goals: $\Delta R^{2}=0.06$} & \multicolumn{4}{|c|}{ Intrinsic goals: $\Delta R^{2}=0.06$} \\
\hline
\end{tabular}


Table 4: Regression extrinsic goals on family structure with general family functioning

\begin{tabular}{|c|c|c|c|c|c|c|c|c|c|c|c|c|}
\hline \multirow[b]{2}{*}{ Extrinsic goals } & \multicolumn{4}{|c|}{ Total sample } & \multicolumn{4}{|c|}{ One parent } & \multicolumn{4}{|c|}{ Two parents } \\
\hline & $b$ & $\mathrm{SE} b$ & B & $t$ & $b$ & $\mathrm{SE} b$ & $B$ & $t$ & $b$ & $\mathrm{SE} b$ & $B$ & $t$ \\
\hline \multicolumn{13}{|l|}{ Step 1} \\
\hline Constant & 1.94 & & & & 2.29 & & & & 1.74 & & & \\
\hline Need satisfaction & 0.24 & 0.06 & $0.20 *$ & 3.79 & 0.17 & 0.11 & 0.13 & 1.49 & 0.27 & 0.08 & $0.24 *$ & 3.54 \\
\hline Need frustration & 0.03 & 0.06 & 0.03 & 0.48 & -0.06 & 0.11 & -0.05 & -0.53 & 0.09 & 0.07 & 0.09 & 1.30 \\
\hline \multicolumn{13}{|l|}{ Step 2} \\
\hline Constant & 1.94 & & & & 2.28 & & & & 1.76 & & & \\
\hline Need satisfaction & 0.24 & 0.06 & $0.20 *$ & 3.79 & 0.17 & 0.11 & 0.12 & 1.47 & 0.27 & 0.08 & $0.24 *$ & 3.54 \\
\hline Need frustration & 0.03 & 0.06 & 0.03 & 0.48 & -0.05 & 0.11 & -0.04 & -0.49 & 0.09 & 0.07 & 0.09 & 1.32 \\
\hline General functioning & -0.01 & 0.08 & -0.00 & -0.02 & 0.04 & 0.13 & 0.03 & 0.34 & -0.08 & 0.10 & -0.05 & -0.78 \\
\hline Step 1: & \multicolumn{4}{|c|}{ Extrinsic goals: $\Delta R^{2}=0.04$} & \multicolumn{4}{|c|}{ Extrinsic goals: $\Delta R^{2}=0.00$} & \multicolumn{4}{|c|}{ Extrinsic goals: $\Delta R^{2}=0.06$} \\
\hline Step 2: & \multicolumn{4}{|c|}{ Extrinsic goals: $\Delta R^{2}=0.03$} & \multicolumn{4}{|c|}{ Extrinsic goals: $\Delta R^{2}=-0.00$} & \multicolumn{4}{|c|}{ Extrinsic goals: $\Delta R^{2}=0.06$} \\
\hline
\end{tabular}

When aspiring to personal growth, the individual aspires to psychological well-being and being intrinsically motivated to function optimally (Deci \& Ryan, 2000), which would aid in strengthening the familial unit (Disabato, Goodman, Kashdan, Short \& Jarden, 2016).

Adolescents from two-parent families aspired to extrinsic goals, which predicted need satisfaction. This association found in two-parent families, can be explained by Brdar, Rijavec, and Miljkovic (2009) who have found that in developing countries, like South Africa, extrinsic goals and aspirations assist in the promotion of well-being. In addition, one could speculate that two-parent families might place more importance on extrinsic goals for prestige and economic advancement.

In terms of basic psychological needs, adolescents in both one- and two-parent families indicated that their needs were satisfied. This finding was similar to that of Roman et al. (2015). It might be that secure parental attachment has health promotion aspects regardless of family structure (Laghi, D'Alessio, Pallini \& Baiocco, 2009). It is often assumed that one-parent families function less well than two-parent families, presumably because one-parent families have limited access to social support in the presence of psychological distress (Jackson, Brooks-Gunn, Huang \& Glassman, 2000). This might not be the case in developing world settings in which the burden of parenting may be shared with extended family (Brdar, Rijavec \& Miljkovic, 2009; Kay \& Spaaij, 2012).

\section{Study limitations}

One of the limitations of the current study was that it employed a cross-sectional design. For that reason, future studies should employ a longitudinal study design to determine if the findings would be replicated. In addition, the sample was limited to in-school adolescents and findings cannot be generalised to adolescents who drop out of the schooling system. Future research should examine the specific domains or components of family functioning which contribute to basic psychological needs fulfilment among typical South African families. 


\section{Conclusion}

Family structure predicted that adolescents will aspire towards intrinsic goals and aspirations especially within one-parent families. This could be explained by adolescents being motivated to succeed and to take responsibility for their actions, which may be similar for two-parent family structures. Satisfaction of psychological needs was found to be the same regardless of family structure, which could be the result of the supportive environment provided by the family environment.

\section{Acknowledgements}

The authors would like to acknowledge the support of the National Research Foundation (NRF). 


\section{References}

Amato, R. (2005). The impact of family formation change on the cognitive, social, and emotional well-being of the next generation. The Future of Children, 15(2), 75-96. http:// dx.doi.org/10.1353/foc.2005.0012.

Basson, W. J. (2013). Helping divorced parents to benefit adolescent children: A prospective enrichment programme. Journal of Psychology in Africa, 23(4), 675678.

Berge, J. M., Wall, M., Larson, N., Loth, K. A., \& Neumark-Sztainer, D. (2013). Family funtioning: Associates with weight status, eating behaviors, and physical activity in adolescents. The Journal of Adolescent Health, 52(3), 351-357. http://dx.doi.org/10.1016/j.jadohealth.2012.07.006.

Brdar, I., Rijavec, M., \& Miljkovic, D. (2009). Life goals and well-being: Are extrinsic aspirations always detrimental to well-being? Psychological Topics, 18(2), 317-334.

Davids, E., \& Roman, N. (2013). Does family structure matter? Comparing the life goals and aspirations of learners in secondary schools. South African Journal of Education, 33(3), 1-12. http://dx.doi.org/10.15700/201503070745.

Davids, E. L., Roman, N. V., \& Leach, L. (2015). The effect of family structure on decisionmaking, parenting styles and healthy lifestyle behaviour of adolescents in rural South Africa. African Journal of Physical, Health Education, Recreation and Dance, 21(3:2), 953-967.

Davids, E. L., Roman, N. V., \& Leach, L. (2016). Decision making styles: A systematic review of their associations with parenting. Adolescent Research Review, 1(1), 69-90. http:// dx.doi.org/10.1007/s40894-015-0003-y.

Deci, E., \& Ryan, M. (2000). The 'what' and 'why' of goal pursuits: Human needs and the self-determination of behavior. Psychological Inquiry, 11(4), 227-268. http:// dx.doi.org/10.1207/S15327965PLI1104_01.

Deci, E. L., \& Ryan, R. M. (2008). Self-determination theory: A macrotheory of human motivation, development and health. Canadian Psychology, 49(3), 182-185. http://dx.doi. org/10.1037/aoo12801.

Disabato, D. J., Goodman, F. R., Kashdan, T. B., Short, J. L., \& Jarden, A. (2016). Different types of well-being? A cross-cultural examination of hedonic and eudaimonic well-being. Psychological Assessment, 28(5), 471-482.

Epstein, N. B., Baldwin, L. M., \& Bishop, D. S. (1983). The McMaster Family Assessment Device. Journal of Marital and Family Therapy, 9(2), 171-180. http://dx.doi. org/10.1111/j.1752-0606.1983.tb01497.x.

Fomby, P., \& Cherlin, A. J. (2007). Family instability and child wellBeing. American Sociological Review, 72(2), 181-204. http://dx.doi.org/10.1177/000312240707200203.

Holborn, C., \& Eddy, G. (2011). First steps to healing the South African family. South African Institute of Race Relations. Retrieved 11 December 2015 from South African Institute of Race Relations: http://www.sairr.org.za/services/ publications/occasional-reports/files/first-steps-to-healing-the-south-africanfamily-final-report-mar-2011.pdf. 
Huebner, A. J., \& Howell, L. W. (2003). Examining the relationship between adolescent sexual risk-taking and perceptions of monitoring, communication, and parenting styles. The Journal of Adolescent Health, 33(2), 71-78. http://dx.doi.org/10.1016/S1054-139X(03)o0141-1.

Jackson, A. P., Brooks-Gunn, J., Huang, C., \& Glassman, M. (2000). Single mothers in low-wage jobs: Financial strain, parenting, and preschoolers' outcomes. Child Development, 71(5), 1409-1423. http://dx.doi. org/10.1111/1467-8624.00236.

Jennings, E. A., \& Barber, J. S. (2013). The influence of neighbours' family size preference on women's progression to higher parity births. Studies in Family Planning, 44(1), 67-84. http://dx.doi.org/10.1111/j.1728-4465.2013.00344.x.

Kasser, T., \& Ryan, M. (1993). A dark side of the American dream: Correlates of financial success as a central life aspiration. Journal of Personality and Social Psychology, 65(2), 410-422. http://dx.doi.org/10.1037/0022-3514.65.2.410.

Kasser, T., \& Ryan, R. M. (1996). Further examining the American dream: Differential correlates of intrinsic and extrinsic goals. Personality and Social Psychology Bulletin, 22(3), 280-287. http://dx.doi.org/10.1177/0146167296223006.

Kay, T., \& Spaaij, R. (2012). The mediating effects of family on sport in international development contexts. International Review for the Sociology of Sport, 47(1), 7794. http:// dx.doi.org/10.1177/1012690210389250.

Koen, V., Van Eeden, C., \& Rothmann, S. (2013). A model for psychosocial well-being of families in a South African context. Journal of Psychology in Africa, 23(1), 155-164.

La Gaurdia, J., \& Ryan, R. (2002). What adolescents need: Self-Determination Theory on development within families, schools and societies. In F. Pajares \& T. Urban (eds), Motivation of Adolescents (pp. 193-219). Connecticut: Information Age Publishing.

Laghi, F., D’Alessio, M., Pallini, S., \& Baiocco, R. (2009). Attachment representations and time perspective in adolescence. Social Indicators Research, 9o(2), 181-194. http://dx.doi.org/10.1007/s11205-008-9249-0.

McLachlan, S., \& Haggar, M. S. (2011). Do people differentiate between intrinsic and extrinsic goals for physical activity? Journal of Sport \& Exercise Psychology, 33(2), $273-288$.

Meinck, F., Cluver, L. D., Boyes, M. E., \& Mhlongo, E. L. (2015). Risk and protective factors for physical and sexual abuse of children and adolescents in Africa: A review and implications for practice. Trauma, Violence \& Abuse, 16(1), 81-107. http://dx.doi.org/10.1177/1524838014523336.

Nqweni, Z. C., Pinderhughes, E. E., \& Hurley, S. (2010). Delinquent adolescents' regrettable behaviours and parental engegement: A cross-cultural comparission. Journal of Psychology in Africa, 20(2), 249-257.

Olaniyi, B., \& Narain, M. (2008). Parental involvement and children's academic achievement in a South Africa setting. Journal of Psychology in Africa, 18(2), 275278.

Roman, N. (2014). The effect of family functioning and basic need satisfaction on decisionmaking styles of adolescents: a rural South African sample. Poster presented at the 
13th Australian Institute of Family Studies Conference: Families in a rapidly changing world. 30 July-1 August 2014, Melbourne, Australia.

Roman, N. V., Davids, E. L., Moyo, A., Schilder, L., Lacante, M., \& Lens, W. (2015). Parenting styles and psychological needs influences on adolescent life goals and aspirations in a South African setting. Journal of Psychology in Africa, 25(4), 305312.

Ryan, R., \& Deci, E. (2004). Handbook of self-determination research. New York: University of Rochester Press.

Sheldon, K. M., \& Hilpert, J. C. (2012). The Balanced Measure of Psychological Needs (BMPN) Scale: An alternative domain general measure of need satisfaction. Motivation and Emotion, 36(4), 439-451. http://dx.doi.org/10.1007/ s11031-0129279-4.

Slep, A. M., \& O'Leary, S. G. (2005). Parent and partner violence in families with young children: Rates, patterns and connections. Journal of Consulting and Clinical Psychology, 73(3), 435-444. http://dx.doi. org/10.1037/0022oo6X.73.3.435.

Stuart, J., Ward, C., \& Robinson, L. (2016). The influence of family climate on stress and adaptation for Muslim migrant young adults in two Western countries. International Perspectives in Psychology: Research, Practice, Consultation, 5(1), 1-17. http://dx.doi.org/10.1037/ ippooooo43.

Thomas, A., \& Sawhill, I. (2005). For love and money? The impact of family structure on family income. The Future of Children, 15(2), 57-74. http://dx.doi.org/10.1353/ foc.2005.0020.

Voydanoff, P. (2001). Incorporating community into work and family research: A review of basic relationships. 54(12), 1609-1637. http://dx.doi.org/10.1177/00187267015412003.

Waldfogel, J., Craigie, T. A., \& Brooks-Gunn, J. (2010). Fragile families and child well-being. The Future of children/Center for the Future of Children, the David and Lucile Packard Foundation, 2O(2), 87-112.

Zarrett, N., \& Eccles, J. (2006). The passage to adulthood: Challenges of late adolescence. New Directions for Youth Development, 2006(111), 13-28. http://dx.doi.org/10.1002/ yd.179.

Zwane, C., Venter, C., Temane, M. Q., \& Chigeza, S. (2012). Black adults' perceptions of healthy family functioning. Journal of Psychology in Africa, 22(1), 43-48. 